\title{
Effect of variety, nitrogen fertilization and regrowth interval on fatty acid levels of perennial ryegrass post establishment
}

\section{Cristilli ${ }^{1}$, M.B. Lynch ${ }^{1}$, D. McGilloway², S. Barth ${ }^{3}$, T.M. Boland ${ }^{1}$}

${ }^{1}$ School of Agriculture, Food Science and Veterinary Medicine, University College Dublin, Belfield, Dublin4, Co.Dublin, Ireland, ${ }^{2}$ Department of Agriculture, Fisheries and Food, Crop Variety Evaluation, Backweston, Leixlip, Co.Kildare, Ireland, ${ }^{3}$ Teagasc Crop Research Centre, Oak Park, Carlow, Co.Carlow, Ireland

Email: marta.cristilli@ucd.ie

Introduction Grassland based ruminant production systems dominate Irish agriculture and perennial ryegrass (PRG) dominates reseeding programs. Perennial ryegrass is a rich source of poly unsaturated fatty acids (PUFA) namely linoleic (C18:2) and linolenic (C18:3) acid in the ruminant diet. Recent work (Cristilli et al., 2009) shows that along with season the variety has a strong effect on fatty acid profile of PRG and offers an avenue to increase the supply of fatty acids to grazing ruminants. Additionally nitrogen fertilization (Boufaied et al., 2003), and cutting interval (Elgersma et al., 2003), have been linked with variation of PUFA concentrations in grass herbage. The objective of this work was to evaluate the effect of variety, nitrogen application level $(\mathrm{N})$ and regrowth interval $(\mathrm{R})$ on the fatty acid profile of PRG in Autumn.

Material and methods A $12 \times 2 \times 2$ factorial design study was carried out to examine the effect of variety, N level and R interval on fatty acid concentration and yield with four replicated fully randomized blocks and twelve PRG (Lolium perenne L.) varieties. Plots $(1.5 \mathrm{~m} \times 4.5 \mathrm{~m})$ were harvested to a post cutting height of $5 \mathrm{~cm}$ using a Haldrup, Logstor, Denmark. Varieties were sown on $26^{\text {th }}$ May 2008. Two N rates: 25 (low, N1) and 70 (high, N2) kg N/ha were applied over the experimental period from July to October 2008, directly after the preceding cut. Regrowth interval were three (short, R1) or five (long, R2) weeks. A one step methylation method (Sukhija and Palmquist, 1988) was used for FA methylation. The FA profile was determined by gas chromatography using a Varian GC (Chromopak) CP-3800 equipped with a FID detector and a CP-7420 column (Varian-Chromopack). Data were analysed using the mixed procedure of SAS with terms included for variety, $\mathrm{N}$ level and $\mathrm{R}$ interval and the associated interactions.

Results The effect of selected varieties, $\mathrm{N}$ level and $\mathrm{R}$ interval on fatty acid content is shown in Table 1. Regrowth interval affected $(\mathrm{P}<0.001)$ total FA and $\mathrm{C} 18: 3$ concentrations, with R1 showing higher levels. Interactions between $\mathrm{R}$ and cut $(\mathrm{P}<0.001)$ were found and manifested through R1 with an increase of FA levels from an early to a late cutting time, and through R2 with an increase of total FA and a decrease of C18:2 and C18:3. No interactions were found between $\mathrm{N}$ level and $\mathrm{R}$ interval in FA levels. Magician presented the highest levels of individual FA while Denver had the lowest levels. Overall, there were no significant effects of variety and $\mathrm{N}$ level on total FA, while $\mathrm{C} 18: 2$ and $\mathrm{C} 18: 3$ were increased by N2. Regarding FA yield, R2, N2 and a late cut positively affected total and individual FA yield. Magician and Gilford presented the highest and the lowest FA yield respectively, with the total FA yield amounting to 90.8 and $69.2 \mathrm{Kg} \mathrm{FA} / \mathrm{ha}$. Interactions between $\mathrm{R}$ interval and $\mathrm{N}$ level $(\mathrm{P}<0.001)$ showed highest FA yields in R2N2 and lowest in R1N1.

Conclusions Fatty acid content of PRG varies with variety and management factors post establishment. A reduction in $\mathrm{R}$ interval lead to an increase in total fatty acid content. Monitoring and manipulation of these factors, together with genetic selection could lead to high lipid varieties and potentially to an increase in the content of essential PUFA in ruminant products.

Acknowledgement Funding for this research was provided under the National Development Plan, through the Research Stimulus Fund, administered by the Department of Agriculture, Fisheries \& Food.

\section{References}

Boufaïed, H., Chouinard, P.Y., Tremblay, G.F., Petit, H.V., Michaud, R. and Belanger, G. 2003. Canadian Journal of Animal Science. 76, 790-797.

Cristilli, M., Lynch, M.B., Barth, S., McGilloway, D., Kenny, D.A., Boland, T.M. 2009. Page 96 in Proceedings of Agricultural Research Forum 2009, Tullamore, Offaly, Ireland.

Elgersma, A., Ellen, G., Van Der Horst, H., Muuse B.G., Boer, H. and Tamminga, S. 2003b. Grass and Forage Science. 58, 323-331.

Sukhija, P.S. and Palmquist, D.L. 1988. Journal of Agricultural and. Food Chemistry. 36, 1202-120. 